\title{
Yield stability in Coffea canephora from diallel mating designs monitored for 14 years
}

\author{
C Cilas ${ }^{1}, \mathrm{P}$ Bouharmont ${ }^{1}$ and A Bar-Hen ${ }^{2}$ \\ ${ }^{1}$ CIRAD-CP, TA 80/03, 34398, Montpellier Cedex 5, France; ${ }^{2}$ Université de Aix-Marseille III, 13397, Marseille, France
}

\begin{abstract}
The genetic parameters of several agronomic traits were estimated in Coffea canephora in a triangular diallel with six parents and in a partial diallel with 18 parents. The yield data came from harvests obtained over 14 years divided into an initial 6-year cycle, a second cycle of 5 years after cutting back and a third cycle of 3 years after topping. Risk incidence was also observed over several years. The general combining abilities (GCA) were the principal sources of variation for the various traits considered. Parents derived from the Yangambi selections (Democratic Republic of Congo) proved to be best for yields in the three cropping cycles. The rank correlations between the GCA of the various traits
\end{abstract}

indicated that first-cycle production was still not enough to predict the GCA for yield over 14 years. Susceptibility to leaf anthracnose and to drought could lead to modifications in successive classifications, with a more significant impact on production during the first cycle. The differences in susceptibility to Coffee Berry Borers had an impact on yield, which increased in line with coffee tree age. There was a rather good relation between inherent values and values in parent combinations and it was thus possible to choose parents on their own performance.

Heredity (2003) 91, 528-532. doi:10.1038/sj.hdy.6800351

Keywords: yield stability; general combining ability; diallel; Coffea canephora

\section{Introduction}

Today, coffee is one of the main agrifood commodities traded worldwide, but fluctuations in green coffee prices penalize intensive cultivation requiring numerous inputs (fertilizers or pesticides). The selection of high-yielding varieties that are resistant to various parasites or climatic adversities has become one of the priority objectives for many producing countries (Bertrand et al, 2000). In order to meet that objective, some research programmes have turned to the creation of hybrids that combine hybrid vigour with greater resistance to adversities. Breeding of Coffea canephora Pierre, a cross-fertilizing species producing the coffee commonly known as 'robusta', has traditionally been based on the selection of full-sib families and clones identified in the best hybrid families (Montagnon et al, 1998a). New genetic improvement strategies have been developed for that species, notably in Côte d'Ivoire, where a reciprocal recurrent selection scheme has been launched (Leroy et al, 1994; Montagnon et al, 1998b).

In Cameroon, 'robusta' cultivation is subjected to highly varied environments; several selection criteria have to be taken into account in the genetic improvement of the species. It is also necessary to establish a long-term selection strategy to enable a continual increase in genetic gains. If such selection is to be successful, it is necessary to estimate genetic parameters relative to the main traits of agronomic interest, and to morphological traits that may be linked to them. It is also necessary to study yield stability in the planting material, notably with a view to determining the number of years required

Correspondence: C Cilas, CIRAD-CP, TA 80/03, 34398, Montpellier Cedex 5, France. E-mail: christian.cilas@cirad.fr

Received 25 September 2002; accepted 17 June 2003 to estimate the productive capacity of trees (Evans and Fischer, 1999). After the selection and dissemination of a clonal mix (Bouharmont and Awemo, 1979), genetic improvement of $C$. canephora in Cameroon turned to interclonal hybrid selection (Bouharmont et al, 1986). Several mating designs have been set up on research stations in Cameroon, to study the performance of hybrids and identify good parents. It is possible through these designs to envisage new varietal outputs for dissemination in robusta growing zones. The transmission of different agronomic traits is examined and an estimation is made of the main genetic parameters. These designs have been used to record yields over 14 consecutive years, resulting in reliable productivity estimations and making it possible to study the stability of this trait over time (Cilas et al, 1985; Dias et al, 1998). In particular, these designs can be used to search for early yield predictors (Walyaro and Van Der Vossen, 1979). Lastly, the production data for parent clones, obtained over two production cycles, are compared to the combining ability estimated in a triangular diallel.

\section{Material and methods}

\section{Planting material}

The coffee trees observed were derived from a triangular diallel type mating design without selfs, and a circular type partial diallel (Kempthorne and Curnow, 1961).

The triangular diallel comprised six parents; the number of crosses carried out was therefore $5 \times 6$ / $2=15$. The six parents came from the 'robusta' coffee collection in Cameroon. Clones B30, B38 and B41 were selected at the Boukoko station in the Central African Republic; clones J8, J26 and J32 came from selections in Java. 
The partial diallel comprised 18 parents; with five crosses per parent, the total number of crosses planted was $5 \times 18 / 2=45$. Parents B2, B5, B7, B8, B10, B14, B16, B19, B25, B26, B36 and B43 were selected at the Boukoko station in the Central African Republic; parents J15 and J19 came from selections in Java; parents N2 and N5 were selected in the Nkongsamba region of Cameroon; parents Y1 and Y2 were selected at the Yangambi research station in the Democratic Republic of Congo.

C. canephora is split into two genetic groups: Guineans from West Africa and Congolese from central Africa (Charrier and Berthaud, 1988). The Congolese genotypes could be split into two subgroups: subgroup 1 containing cultivated varieties originating from Benin and Gabon, and subgroup 2 containing wild genotypes and cultivated origins from central Africa (Montagnon et al, 1998a). The clones used in these studies came from the subgroup 2 of the Congolese population, except J clones, pertaining to Congolese group, for which the subgroup is unspecified.

The coffee trees of the 15 crosses in the first trial were planted in 1974 in a six-block design at the Ambaka station in eastern Cameroon. The elementary plots comprising one row of 10 trees were randomized inside each block. One elementary plot was set up per cross and per block.

The coffee trees of the 45 crosses in the second trial were planted in 1975 in a five-block design at the Barombi-Kang station in the west of the country, near Mount Cameroon. The elementary plots also consisted of one row of 10 trees.

The trees were planted $3 \mathrm{~m} \times 3 \mathrm{~m}$ apart in the first trial and $3.5 \mathrm{~m} \times 2.5 \mathrm{~m}$ apart in the second. The coffee trees in both trials were grown on multiple stems without shading.

\section{Methods}

Yields per elementary plot were recorded over 14 consecutive years: during the first production cycle which lasted 6 years, then after cutting back, during a second cycle lasting 5 years and finally during the first 3 years of the third cycle after topping at the end of the second cycle. Yields were expressed in kilograms of merchantable coffee harvested. In order to compare the different cycles with each other, the yields in each cycle were divided by the number of years taken into account.

In 1980, a score for resistance to leaf anthracnose, a disease caused by Colletotrichum coffeanum Noack., was attributed to the coffee trees in the first trial, on an arbitrary scale ranging from 0 (no diseased leaves) to 5 (a very large number of diseased leaves). Similar scores were attributed to the coffee trees in the second trial in April 1978 and in May 1978 on a scale ranging from 0 to 8.

For the first trial, drought resistance scores were attributed in February 1979 and February 1986. The score in 1979 was based on the number of dry leaves, ranging from 0 (no dry leaves) to 8 (virtually all dry leaves). The score in 1986 corresponded to the quantitative variable 'number of primary branches with dry leaves per elementary plot'. For the second trial, a single score based on the number of dry leaves was attributed in February 1982. Percentages of fruits bored by Coffee Berry Borer (CBB) were also observed for each elemen- tary plot. A recapitulation of the different variables observed is given in Table 1.

The diallel analyses were then carried out using the model of Griffing (1956) for the first trial and the partial diallel model for the second trial (Kempthorne and Curnow, 1961):

$$
P_{i j k}=\mu+g_{i}+g_{j}+s_{i j}+b_{k}+E_{i j k}
$$

where $P_{i j k}$ is the phenotypic value of cross $i \times j$ in block $k$, $g_{i}$ the general combining ability (GCA) of parent $i, s_{i j}$ the specific combining ability of cross $i \times j, b_{k}$ the effect of block $k$ and $E_{i j k}$ the residual error of variance $\sigma^{2}$.

Multivariate analyses provided access to the covariances and correlations between the variables studied for the different factors considered. Application of the genetic model then made it possible to estimate heritabilities and the genetic and phenotypic correlations between the traits studied (Baradat et al, 1995).

The GCA of the parents were compared by the Newman and Keuls test for the different traits considered.

The rank correlations between the GCA of the different traits were estimated in order to study additive genetic links between these traits. The relations between the inherent values of the clones and their GCA were also studied.

\section{Results}

The main trait to be improved was the cumulated yield over 14 years (variable ' $Y d 14^{\prime}$ '). The mean for that trait amounted to $1568 \mathrm{~kg}$ of merchantable coffee per hectare per year for the first trial and $1253 \mathrm{~kg}$ for the second trial. In the first trial, the best two full-sib families came from crosses J32 × B30 and B41 × B30 with yields of 1940 and $1930 \mathrm{~kg} / \mathrm{ha} /$ year, respectively, that is more than double that of the least productive family $(\mathrm{J} 8 \times \mathrm{J} 26: 925 \mathrm{~kg} / \mathrm{ha} /$ year). In the second trial, the best family $(\mathrm{B} 25 \times \mathrm{Y} 2)$ gave annual yields of $2044 \mathrm{~kg}$ of merchantable coffee per hectare, that is almost triple that of the least productive family $(\mathrm{J} 15 \times \mathrm{J} 19)$, which produced $712 \mathrm{~kg}$ of merchantable coffee per hectare per year.

\section{Diallel analyses}

The diallels were analysed for all the traits observed. A strong GCA was detected for the different traits in both trials (Table 2). The specific combining ability (SCA) was low and only significant for second cycle production, and for the 1979 drought score in the first trial. On the other hand, although the SCA were well below the GCA, they

Table 1 List of traits observed per coffee tree

\begin{tabular}{ll}
\hline Name of the variable & Traits observed \\
\hline$Y d 14$ & $\begin{array}{l}\text { Annual mean of the cumulation over three } \\
\text { production cycles (14 years) }\end{array}$ \\
$Y d 1 c, Y d 2 c, Y d 3 c$ & $\begin{array}{l}\text { Annual means of the three production cycles } \\
\text { anthr }\end{array}$ \\
$d r y 79$ & Leaf anthracnose resistance score \\
$d r y 82$ & Drought score in 1979 (first trial) \\
$d r y 86$ & Drought score in 1986 (second trial) \\
$C B B$ & Drought score in 1986 (first trial) \\
& Percentage of berries attacked by \\
& $\begin{array}{l}\text { Hypothenemus hampei (Coffee Berry Borer) in } \\
\text { the second trial }\end{array}$ \\
\hline
\end{tabular}


were significant for the second trial, except for the CBB susceptibility score. As an indication, the random effects analyses were used to estimate heritability in both the narrow sense and the broad sense. The broad sense heritability values were maximum for production cumulated over 14 years, with $h^{2}=0.46$ and 0.52 for the first and second trials, respectively.

The parents were classed for the GCA of the different traits using the Newman and Keuls multiple comparisons test (Tables $3 a$ and $b$ ). For both trials, the parents that performed least well came from the Java selections (J8, J26, J15 and J19). The best two parents in the second trial were from the Yangambi selections (Y1 and Y2). The order of the parents for the different production cycles was not stable in the first trial, whereas it seemed more stable in the second trial. In particular, for the first trial, the GCA classification for first cycle production did not correspond to that of the GCA for production cumulated over 14 years.
The rank correlations for additive genetic effects are shown in Table 4. For both trials, the correlations indicated that good prediction of cumulated production could be achieved using second cycle production. The GCA for the drought resistance and leaf anthracnose resistance scores were well correlated with each other in the first trial, hence reactions to these two adversities were linked. First cycle production was not sufficient for predicting production cumulated over 14 years in the first trial. It therefore seemed important to add additional variables to first cycle production to predict yields cumulated over 14 years. In this trial, the changes in the classification over the different production cycles could be explained by the drought and/or leaf anthracnose resistance scores. Susceptibility to anthracnose penalized first cycle production more, with a rank correlation of -0.829 , which was significant. For example, parent B41, which transmitted the greatest susceptibility to drought and substantial susceptibility to

Table 2 Value of Fisher tests associated with the GCA and SCA and probabilities (\%)

\begin{tabular}{|c|c|c|c|c|}
\hline \multirow[t]{2}{*}{ Variables } & \multicolumn{2}{|c|}{ First trial (residual: $70 \mathrm{df}$ ) } & \multicolumn{2}{|c|}{ Second trial (residual: $176 \mathrm{df})$} \\
\hline & $G C A(5 d f)$ & $S C A(9 d f)$ & GCA (17df) & $S C A(27 d f)$ \\
\hline$Y d 14$ & $33.15(<0.001)$ & $2.00(5.157)$ & $26.17(<0.001)$ & $2.76(0.004)$ \\
\hline$Y d 1 c$ & $15.87(<0.001)$ & $1.90(6.624)$ & $16.50(<0.001)$ & $2.85(0.002)$ \\
\hline$Y d 2 c$ & $21.33(<0.001)$ & $2.06(4.442)$ & $18.04(<0.001)$ & $2.49(0.022)$ \\
\hline$Y d 3 c$ & $34.17(<0.001)$ & $1.40(20.307)$ & $18.83(<0.001)$ & $1.93(0.631)$ \\
\hline Anthr & $15.22(<0.001)$ & 1.65 (11.725) & $12.28(<0.001)$ & $2.11(0.217)$ \\
\hline dry79/82 & $15.10(<0.001)$ & $2.12(3.895)$ & $12.29(<0.001)$ & $2.28(0.080)$ \\
\hline dry $86 / C B B$ & $8.65(<0.001)$ & $1.62(12.515)$ & $3.45(0.002)$ & $0.60(94.422)$ \\
\hline
\end{tabular}

Table 3 Comparison of parents for estimated GCA

\begin{tabular}{|c|c|c|c|c|c|c|c|}
\hline $\begin{array}{l}\text { (a) First trial } \\
\text { Parent }\end{array}$ & $Y d 14$ & $Y d 1 c$ & $Y d 2 c$ & $Y d 3 c$ & anthr & $d r y 79$ & dry 86 \\
\hline B30 & $226 \mathrm{a}$ & $141 \mathrm{a}$ & $235 \mathrm{a}$ & 383 a & $-0.356 \mathrm{ab}$ & $-0.469 \mathrm{a}$ & $-23.3 \mathrm{a}$ \\
\hline B38 & $126 \mathrm{ab}$ & $102 \mathrm{a}$ & $147 \mathrm{a}$ & $141 \mathrm{~b}$ & $-0.065 \mathrm{bc}$ & $0.068 \mathrm{~b}$ & $7.8 \mathrm{~b}$ \\
\hline B41 & $123 \mathrm{ab}$ & $-6 b$ & $93 \mathrm{a}$ & 433 a & $0.508 \mathrm{~d}$ & 0.531 c & $29.9 \mathrm{~b}$ \\
\hline J32 & $76 \mathrm{~b}$ & 149 a & 113 a & $-133 c$ & $-0.669 \mathrm{a}$ & $-0.728 \mathrm{a}$ & $-22.7 \mathrm{a}$ \\
\hline J8 & $-143 c$ & $-177 \mathrm{c}$ & $-90 \mathrm{~b}$ & $-164 c$ & $0.521 \mathrm{~d}$ & $0.689 \mathrm{c}$ & $23.8 \mathrm{~b}$ \\
\hline $\mathrm{J} 26$ & $-409 \mathrm{~d}$ & $-210 \mathrm{c}$ & $-497 \mathrm{c}$ & $-661 d$ & $0.062 \mathrm{c}$ & $-0.090 \mathrm{~b}$ & $-15.4 \mathrm{a}$ \\
\hline \multicolumn{8}{|c|}{ (b) Second trial } \\
\hline Y2 & $391 \mathrm{a}$ & $278 \mathrm{ab}$ & $347 \mathrm{a}$ & $652 \mathrm{a}$ & $3.71 \mathrm{bc}$ & -0.124 def & $-4.51 \mathrm{bc}$ \\
\hline Y1 & $287 \mathrm{ab}$ & $245 \mathrm{ab}$ & 366 a & $226 \mathrm{bc}$ & $-5.48 \mathrm{fgh}$ & $-0.773 \mathrm{i}$ & $-2.83 \mathrm{bc}$ \\
\hline B25 & 208 bc & 312 a & $200 \mathrm{abc}$ & 48 cde & $15.17 \mathrm{a}$ & -0.102 def & $-0.65 \mathrm{bc}$ \\
\hline B10 & 208 bc & $158 \mathrm{bc}$ & $243 \mathrm{ab}$ & 234 bc & -4.21 efgh & 0.277 abcd & $-3.14 b c$ \\
\hline B36 & 192 bc & $84 \mathrm{c}$ & $252 \mathrm{ab}$ & $268 \mathrm{~b}$ & -1.16 cdef & $-0.465 \mathrm{gh}$ & $-3.75 \mathrm{bc}$ \\
\hline B5 & $141 \mathrm{~cd}$ & $73 \mathrm{~cd}$ & $186 \mathrm{abc}$ & $181 \mathrm{bcd}$ & -3.11 efgh & 0.064 bcde & $3.04 \mathrm{abc}$ \\
\hline B14 & $48 \mathrm{de}$ & $-16 \mathrm{~cd}$ & $169 \mathrm{abc}$ & $-47 \mathrm{e}$ & $-7.67 \mathrm{~h}$ & -0.052 cdef & $3.45 \mathrm{abc}$ \\
\hline B19 & 27 def & $-10 \mathrm{~cd}$ & $63 \mathrm{bcd}$ & 28 cde & -3.33 efgh & $0.233 \mathrm{abcd}$ & $1.40 \mathrm{abc}$ \\
\hline B26 & 21 def & $23 \mathrm{~cd}$ & 18 cde & 24 cde & $6.14 \mathrm{~b}$ & $-0.359 \mathrm{fgh}$ & $-3.08 \mathrm{bc}$ \\
\hline B7 & $-23 \mathrm{efg}$ & $38 \mathrm{~cd}$ & -97 defg & -3 de & -2.41 efgh & $0.230 \mathrm{abcd}$ & $-1.75 \mathrm{bc}$ \\
\hline B16 & -31 efg & $70 \mathrm{~cd}$ & -48 def & $-172 \mathrm{e}$ & $6.08 \mathrm{~b}$ & $0.239 \mathrm{abcd}$ & $3.23 \mathrm{abc}$ \\
\hline B2 & -64 efg & $-27 \mathrm{~cd}$ & -150 efg & 17 cde & 0.43 cde & $0.518 \mathrm{a}$ & $-5.05 c$ \\
\hline N5 & $-114 \mathrm{fg}$ & $-37 \mathrm{~cd}$ & -157 efg & $-172 \mathrm{e}$ & $-7.02 \mathrm{gh}$ & $-0.510 \mathrm{hi}$ & 8.97 a \\
\hline B8 & $-128 \mathrm{fg}$ & -118 de & -151 efg & $-108 \mathrm{e}$ & $3.15 \mathrm{bcd}$ & $0.350 \mathrm{abc}$ & $-3.41 \mathrm{bc}$ \\
\hline B43 & $-168 \mathrm{~g}$ & $-118 \mathrm{de}$ & $-220 \mathrm{fg}$ & $-163 \mathrm{e}$ & -1.82 defg & $0.393 \mathrm{ab}$ & $5.55 \mathrm{ab}$ \\
\hline N2 & $-229 \mathrm{~g}$ & -230 ef & $-285 \mathrm{~g}$ & $-135 \mathrm{e}$ & 3.37 bcd & $0.210 \mathrm{abcd}$ & $-0.70 \mathrm{bc}$ \\
\hline J19 & $-356 h$ & $-368 \mathrm{f}$ & $-280 \mathrm{~g}$ & $-462 \mathrm{f}$ & -2.85 efgh & 0.053 bcde & $5.05 \mathrm{abc}$ \\
\hline J15 & $-410 \mathrm{~h}$ & $-358 \mathrm{f}$ & $-458 \mathrm{~h}$ & $-416 \mathrm{f}$ & 0.98 bcde & -0.180 efg & $-1.82 \mathrm{bc}$ \\
\hline
\end{tabular}

Values with the same letter in a column are not significantly different according to Newman and Keuls multiple range test $(P=0.05)$. 
Table 4 Rank correlations between general combining abilities for the different traits (associated probabilities) (first trial: upper half; second trial: lower half)

\begin{tabular}{|c|c|c|c|c|c|c|c|}
\hline & $Y d 14$ & $Y d 1 c$ & $Y d 2 c$ & $Y d 3 c$ & anthr & dry79/82 & dry 86 \\
\hline$Y d 14$ & 1 & $0.657(0.156)$ & $0.943^{*}(0.005)$ & $0.829 *(0.042)$ & $-0.429(0.397)$ & $-0.200(0.704)$ & $-0.257(0.623)$ \\
\hline$Y d 1 c$ & $0.948^{*}(<0.001)$ & 1 & $0.829 *(0.042)$ & $0.486(0.329)$ & $-0.829 *(0.042)$ & $-0.657(0.156)$ & $-0.543(0.266)$ \\
\hline$Y d 2 c$ & $0.983^{*}(<0.001)$ & $0.924^{*}(<0.001)$ & 1 & $0.657(0.156)$ & $-0.657(0.156)$ & $-0.429(0.397)$ & $-0.486(0.329)$ \\
\hline$Y d 3 c$ & $0.901^{*}(<0.001)$ & $0.830 *(<0.001))$ & $0.895^{*}(<0.001)$ & 1 & $-0.143(0.787)$ & $0.029(0.957)$ & $0.143(0.787)$ \\
\hline anthr & $-0.088(0.729)$ & $0.088(0.729)$ & $-0.121(0.633)$ & $-0.028(0.912)$ & 1 & $0.943^{*}(0.005)$ & $0.829 *(0.042)$ \\
\hline dry79/82 & $-0.309(0.213)$ & $-0.255(0.307)$ & $-0.307(0.216)$ & $-0.197(0.433)$ & $0.094(0.711)$ & 1 & $0.886(0.019)$ \\
\hline$C B B$ & $-0.350(0.155)$ & $-0.333(0.177)$ & $-0.379(0.121)$ & $-0.593^{*}(0.009)$ & $-0.360(0.142)$ & $-0.020(0.938)$ & 1 \\
\hline
\end{tabular}

${ }^{*}$ Correlation significant at $5 \%$.

Table 5 Rank correlations between general combining abilities and inherent values of the clones (associated probabilities)

\begin{tabular}{lcccrrrr}
\hline & $Y d 14$ & $Y d 1 c$ & $Y d 2 c$ & $Y d 3 c$ & $Y d 12 c$ & $d r y 79$ & \\
\hline$Y d 12 c P$ & $0.543(0.266)$ & $0.943^{*}(0.005)$ & $0.771(0.072)$ & $0.257(0.623)$ & $0.886^{*}(0.019)$ & $-0.600(0.208)$ & $-0.314(0.623)$ \\
$d r y P$ & $-0.314(0.544)$ & $-0.771(0.072)$ & $-0.600(0.208)$ & $0.086(0.872)$ & $-0.714(0.111)$ & $0.886^{*}(0.019)$ & $0.886^{*}(0.019)$
\end{tabular}

*Significant correlations.

$Y d 12 c$ : production in the first two cycles (GCA); $Y d 12 c P$ : production of the parent clones over the first two cycles; dryP: drought resistance score attributed to the parent clones.

anthracnose to its progeny, became the best parent for third cycle production, whereas it only came fourth for production in the first two cycles. In fact, the impact of drought decreased as the coffee trees grew older with a more developed root system. On the other hand, the GCA for production in the different cycles were well correlated with each other and with the 14-year cumulation in the second trial. In that trial, the GCA for reactions to anthracnose and drought were not significantly correlated to those for the production variables; this could be explained by less limiting environmental conditions than in the first trial. The differences in susceptibility to CBB had an impact on the GCA for the production traits, notably in the third cycle, for which the GCA was significantly correlated to the GCA for susceptibility to CBB.

\section{Relation between GCA and inherent values}

The yield data for parent clones in the first trial were obtained over two production cycles in clonal comparative trials. Drought susceptibility scores were also attributed to these clones. It was therefore possible to study the relation between the inherent values and combination values of the study clones for each of these traits. The rank correlations were significant for production cumulated over the first two cycles and the drought susceptibility score (Table 5). The greatest rank correlation was obtained between the GCA for first cycle production and the production of the parents cumulated over the first two cycles.

\section{Discussion}

An analysis of the diallel studied revealed mainly additive transmission of the traits taken into account, with highly significant GCA values that were always greater than the SCA effects. The most heritable trait was production cumulated over 14 years. Indeed, a large number of years made it possible to overcome annual particularities, notably climatic conditions, resulting in a reduction of environmental effects. The classifications of parents according to their GCA indicated that robusta coffee tree selections from Java performed less well for production traits. The best parents came from Yangambi selections (Democratic Republic of Congo).

First cycle production, which was recorded over 6 years, was still not enough to obtain a reliable parent classification for longer term yields. The differences in susceptibility to leaf anthracnose might explain the changes in classification between successive cycles. Leaf anthracnose and drought were, in fact, more detrimental to first cycle production than to production in the following cycles (Bouharmont and Awemo, 1979). When these adversities were less, as in the second trial, first cycle production was a good predictor of longer term cumulated yields. In addition, topping before the third cycle undoubtedly induced different reactions depending on the planting material. The GCA for CBB susceptibility was negatively correlated with that for production, and this correlation became significant in the third production cycle.

It would be worth monitoring other mating designs over fairly long periods, in order to understand the changes in classification observed over consecutive production cycles. In that respect, it would be wise to observe architectural traits on coffee trees in the trial, to ascertain the productive capacity of the trees (De Reffye, 1979; Cilas et al, 1998; Godin, 2000). Indeed, production is merely the fulfilment of productive potential subjected to agronomic and phytosanitary constraints, and that productive potential partly depends on the growth strategy of the trees. Such studies would complete work carried out on production stability in space, and studies on genotype $\times$ environment interactions (Agwanda et al, 2000).

There was a fairly good relation between inherent values and combination values for the clones studied, which confirmed earlier studies (Bouharmont et al, 1986). It is therefore possible to choose parents according to their inherent performance. 
This study also needs to be completed with an analysis of technological traits, and possibly sensorial traits, in order to proceed with family selection combining both agronomic and organoleptic qualities.

\section{Acknowledgements}

We would like to thank Peter Biggins for the translation.

\section{References}

Agwanda CO, Baradat P, Cilas C, Charrier A (2000). Prediction of yield stability in arabica coffee based on the stability of morphological components. In: Proceedings of the XVIIIth International Scientific Conference on Coffee. Helsinki, Finland, 2-6 August 1999, pp 452-453.

Baradat Ph, Labbé T, Bouvet JM (1995). Conception d'index pour la sélection réciproque récurrente: aspects génétiques, statistiques et informatiques. In: CIRAD (ed) Traitements statistiques des essais de sélection,. Montpellier: France. pp 101-150.

Bertrand B, Peña Durán MX, Anzueto F, Cilas C, Etienne H, Anthony F, Eskes AB (2000). Genetic study of Coffea canephora coffee tree resistance to Meloidogyne incognita nematodes in Guatemala and Meloidogyne sp. nematodes in El Salvador for selection of rootstock varieties in Central America. Euphytica 113: 79-86.

Bouharmont P, Awemo J (1979). La sélection végétative du caféier Robusta au Cameroun. 1ère Partie: Programme de sélection. Café Cacao Thé 23: 227-254.

Bouharmont P, Lotodé R, Awemo J, Castaing X (1986). La sélection générative du caféier Robusta au Cameroun. Analyse des résultats d'un essai d'hybrides diallèle partiel implanté en 1973. Café Cacao Thé 30: 93-112.

Charrier A, Berthaud J (1988). Principles and methods in coffee plant breeding: Coffea canephora Pierre. In: Clarke RJ, Macrae R (eds) Coffee, Vol 4, Agronomy,. Elsevier Applied Science Ed.: London. pp 167-197.
Cilas C, Amefia YK, Legrand B, Pelissou H (1985). Etude de la stabilité du caractère de productivité chez le cacaoyer. Premières constatations et perspective de sélection. Café Cacao Thé 29: 89-94.

Cilas C, Bouharmont P, Boccara M, Eskes AB, Baradat Ph (1998). Prediction of genetic value for coffee production in Coffea arabica from a half-diallel with lines and hybrids. Euphytica 104: 49-59.

De Reffye Ph (1979). Modélisation de l'architecture des arbres par des processus stochastiques. Simulation spatiale des modèles tropicaux sous l'effet de la pesanteur. Application au Coffea robusta. Thesis, Université de Paris-Sud. 196pp.

Dias LAS, Souza CAS, Augusto SG, Sigueria PR, Müller MW (1998). Performance and temporal stability analyses of cacao cultivars in Linhares. Plantations, Recherches, Développement 5: 343-355.

Evans LT, Fischer RA (1999). Yield potential: its definition, measurement, and significance. Crop Sci 39: 1544-1551.

Godin C (2000). Representing and encoding plant architecture: a review. Ann For Sci 57: 413-438.

Griffing B (1956). Concept of general and specific combining ability in relation to diallel crossing systems. Aust J Biol Sci 9: 463-473.

Kempthorne O, Curnow RN (1961). The partial diallel cross. Biometrics 17: 229-250.

Leroy T, Montagnon C, Cilas C, Charrier A (1994). Reciprocal recurrent selection applied to Coffea canephora Pierre. II. Estimation of genetic parameters. Euphytica 74: 121-128.

Montagnon C, Leroy T, Eskes AB (1998a). Amélioration variétale de Coffea canephora. I. Critères et méthodes de sélection. Plantations, Recherches, Développement 5: 18-33.

Montagnon C, Leroy T, Eskes AB (1998b). Amélioration variétale de Coffea canephora. II. Les programmes de sélection et leurs résultats. Plantations, Recherches, Développement 5: 89-98.

Walyaro DJ, Van Der Vossen HAM (1979). Early determination of yield potential in Arabica coffee by applying index selection. Euphytica 28: 465-472. 